Original Article

\title{
Fat intake interacts with polymorphisms of Caspase9, FasLigand and PPARgamma apoptotic genes in modulating Crohn's disease activity
}

\author{
Paula Ferreira ${ }^{a}$, Marília Cravo ${ }^{b}$, Catarina Sousa Guerreiro ${ }^{\mathrm{a}, \mathrm{c}}$, Lourdes Tavares ${ }^{\mathrm{d}}$, Paula Moura Santos ${ }^{\mathrm{d}}$, \\ Miguel Brito ${ }^{\mathrm{a}, *}$ \\ ${ }^{a}$ Escola Superior de Tecnologia da Saúde de Lisboa, Lisboa, Portugal \\ ${ }^{\mathrm{b}}$ Serviço de Gastrenterologia do Instituto Português de Oncologia Francisco Gentil, EPE, Lisboa, Portugal \\ ${ }^{c}$ Unidade de Nutrição e Metabolismo do Instituto de Medicina Molecular da Universidade de Lisboa, Lisboa, Portugal \\ d Serviço de Gastrenterologia do Hospital de Santa Maria, EPE, Lisboa, Portugal
}

\section{A R T I C L E I N F O}

\section{Article history:}

Received 30 March 2010

Received in revised form

24 May 2010

Accepted 14 June 2010

\section{Keywords:}

Crohn's disease

Caspase 9

Fas Ligand protein

PPAR gamma

Polymorphisms

Fat intake

\begin{abstract}
S U M M A R Y
Background E aims: Crohn's disease (CD) is a multifactorial disease where resistance to apoptosis is one major defect. Also, dietary fat intake has been shown to modulate disease activity. We aimed to explore the interaction between four single nucleotide polymorphisms (SNPs) in apoptotic genes and dietary fat intake in modulating disease activity in CD patients.

Methods: Polymerase Chain Reaction (PCR) and Restriction Fragment Length Polymorphism (RFLP) techniques were used to analyze Caspase9+93C/T, FasLigand-843C/T, Peroxisome Proliferator-Activated Receptor gamma $+161 \mathrm{C} / \mathrm{T}$ and Peroxisome Proliferator-Activated Receptor gamma Pro12Ala SNPs in 99 patients with CD and 116 healthy controls. Interactions between SNPs and fat intake in modulating disease activity were analyzed using regression analysis.

Results: None of the polymorphisms analyzed influenced disease susceptibility and/or activity, but a high intake of total, saturated and monounsaturated fats and a higher ratio of $n-6 / n-3$ polyunsaturated fatty acids(PUFA), was associated with a more active phenotype $(p<0.05)$. We observed that the detrimental effect of a high intake of total and trans fat was more marked in wild type carriers of the Caspase $9+93 \mathrm{C} / \mathrm{T}$ polymorphism [O.R(95\%CI) 4.64(1.27-16.89) and O.R(95\%CI) 4.84(1.34-17.50)]. In the Peroxisome Proliferator-Activated Receptor gamma Pro12Ala SNP, we also observed that a high intake of saturated and monounsaturated fat was associated to a more active disease in wild type carriers [OR(95\%CI) 4.21 (1.33-13.26) and 4.37(1.52-12.51)]. Finally, a high intake of n-6 PUFA was associated with a more active disease in wild type carriers for the FasLigand-843C/T polymorphism [O.R(95\%CI) 5.15(1.07-24.74)].

Conclusions: To our knowledge, this is the first study to disclose a synergism between fat intake and SNPs in apoptotic genes in modulating disease activity in CD patients.
\end{abstract}

(C) 2010 Elsevier Ltd and European Society for Clinical Nutrition and Metabolism. All rights reserved.

\section{Introduction}

Crohn's disease (CD) is a chronic inflammatory disease characterized by a transmural and discontinuous inflammation of the intestinal wall. Although the precise etiology of this disease is unknown, most authors believe that the on-going inflammation results from the interaction between genetic and environmental factors, namely bacterial flora and luminal nutrients. ${ }^{1,2}$ Among the

\footnotetext{
* Corresponding author at. Escola Superior de Tecnologia da Saúde de Lisboa, Av. D. João II lote 4.69.01, 1990-096 Lisboa, Portugal. Tel.: +351 218980400; fax: +351218980460 .

E-mail address: miguel.brito@estesl.ipl.pt (M. Brito).
}

most probably involved pathogenetic mechanisms is the imbalance between proinflammatory and anti-inflammatory cytokines as well as the resistance of the inflammatory cells to apoptotic stimuli., Both of these abnormalities are believed to contribute to perpetuate the inflammation in $\mathrm{CD}$.

On the other hand, some studies have focused on the nutritional manipulation of inflammation, namely through the administration of n-3 fatty acids. ${ }^{5}$ As opposed to n-3 PUFA, and contrary to what was formerly expected, monounsaturated acids may have a detrimental effect, ${ }^{6}$ whereas a recent study showed that medium-chain triglycerides (MCT) may exhibit an anti-inflammatory effect in an experimental model of colitis. ${ }^{7}$ In this regard, Gassull et al., believe that the pro or anti-inflammatory effect of fat depends more on a certain fatty acid profile than on a single fatty acid. ${ }^{6}$ The exact mechanism whereby 
these agents interfere with inflammation is still not fully understood, but probably relates to its ability of reducing the secretion of proinflammatory cytokines as well as to its capacity of inducing apoptosis, as has been shown in previous studies. ${ }^{8}$

However, the beneficial or deleterious effect of the fatty acids is not consistently observed in all studies performed. One reason for these discrepancies could be ascribed to polymorphisms of cytokine genes. ${ }^{9}$ Thus, Grimble et al. ${ }^{10}$ have shown that in a group of healthy individuals, different genotypes for TNFa were not only associated with different levels of TNFa production, but also with different responses to the anti-inflammatory effects of fish oil. Consistent with this hypothesis, in a previous study performed by our group in this same population and aimed at examining the interaction between genetic polymorphisms of pro and antiinflammatory cytokines and fat intake, we observed that different types of fat did interact with cytokine genotype, modulating disease activity. ${ }^{11}$

Similarly, in the present study we explored the interaction between fat intake and four single nucleotide polymorphisms in apoptotic genes namely Caspase-9, FasLigand and Peroxisome Proliferator-Activated Receptor gamma in modifying both susceptibility for $\mathrm{CD}$ as well as disease activity.

\section{Materials and methods}

\subsection{Subjects}

Ninety nine consecutive outpatients with a confirmed diagnosis of $\mathrm{CD}$, who were coming for a routine visit to the outpatient clinic of the two hospitals involved in the study, during the period between September 2004 and November 2007, were asked to participate in the study. Demographic and clinical characteristics of study population have been described previously. ${ }^{11}$ The diagnosis was based on previously defined criteria ${ }^{12}$ and disease activity was assessed according to Harvey and Bradshaw Index. ${ }^{13}$ None of the patients was on steroids at the time of the study and none was hospitalized. Only patients with mild to moderate disease were included. The reason for that was because we intended to analyze the association between nutritional intake during the last year and pattern of disease activity during this same period. Thus, it would be a major bias if we included patients hospitalized for severe disease. Patients with severe active disease $(\mathrm{HBI}>7)$ at the time of patient inclusion or with need of systemic steroids were excluded $(n=7)$. One hundred and sixteen healthy blood donors from the Instituto Português de Oncologia Francisco Gentil S.A (IPOFG), with no previous history of inflammatory bowel disease (IBD), were recruited as a control group for genotyping.

\subsection{Laboratory methods}

Blood samples from CD patients were collected from the institutions previously mentioned and the DNA extraction was performed with phenol/chloroform extraction, ${ }^{14}$ while for controls, the DNA extraction was made from blood samples with methodology described in Generation Capture Card Kit - DNA Purification/DNA Elution (Gentra Systems, Inc., Minneapolis).

Polymerase chain reaction (PCR) and restriction fragment length polymorphism (RFLP) techniques were used to analyze gene polymorphisms in the CASP9, FASLG and PPAR $\gamma$ genes in 99 patients with $\mathrm{CD}$ and 116 controls.

PCR reaction mixture included $10 \times$ buffer ([Taq buffer $\left.\left.+\left(\mathrm{NH}_{4}\right)_{2} \mathrm{SO}_{2}\right]\right), 25 \mathrm{mM} \mathrm{MgCl} 2,2 \mathrm{mM}$ dNTPs, $6 \mu \mathrm{M}$ forward/reverse primer, $5 \mathrm{U} / \mu \mathrm{l}$ Taq DNA polymerase and $\mathrm{H}_{2} \mathrm{O}$ until the final volume of $20 \mu \mathrm{l}$. Primer sequences of the polymorphisms in study: CASP9+93C/T (F: 5'- GGAAGAGCTGCAGGTGGAC -3'/R: 5' - ATGGCAT
GGAATCGCTTTAG -3'), FASLG-843C/T (F:5'- TGGGCAAACAATGAA AATGA -3'/R: 5' - TCATCTCTTCCCCACACACA -3'), PPAR $\gamma+161 \mathrm{C} / \mathrm{T}$ (F: 5'- TGAATGTGAAGCCCATTGAA -3'/R: 5'- TGGAAGAAGGGAAATG TTGG $-3^{\prime}$ ) and PPAR $\gamma$ Pro12Ala (F: 5'- ACTCTGGGAGATTCTCCT ATTGGC -3'/R: 5' - CGATAGCAACGAGCTAAGCA - $3^{\prime}$ ).

RFLP reaction mixture included 10x appropriate reaction buffer (New England Biolabs (NEB)), $0.08 \mathrm{U} / \mu \mathrm{L}$ NruI for CASP9+93C/T, 0.17 $\mathrm{U} / \mu \mathrm{L}$ BsrdI for FASLG-843C/T, $0.04 \mathrm{U} / \mu \mathrm{L}$ PmlI for PPAR $\gamma+161 \mathrm{C} / \mathrm{T}$ and $0.09 \mathrm{U} / \mu \mathrm{L}$ HaelII for PPAR $\gamma$ Pro12Ala (New England Biolabs (NEB)), $100 \mu \mathrm{g} / \mathrm{ml}$ BSA for BsrdI and PmlI enzymes and $\mathrm{H}_{2} \mathrm{O}$ until the final volume of $30 \mu \mathrm{l}$. The reaction took place for $2 \mathrm{~h}$ at $37^{\circ} \mathrm{C}$, except for BsrdI that digests at $65^{\circ} \mathrm{C}$.

After digestion, the product was run in a $4 \%$ gel electrophoresis and, according to the restriction profile, the genotypes for each subject were recorded.

\subsection{Nutritional intake evaluation}

For quantification of the nutrients intake we used a Food Frequency Questionnaire, ${ }^{15}$ validated for the Portuguese population. Participants were asked to recall their habits in the year before the interview. Colored photographs of most food items, showing 3 different portions sizes, as well as measuring cups and spoons were used to facilitate quantification of intake. Type and quantity of food intake was then analyzed in a modified database Food Processor software, version 7 (Esha Research, Inc, Salem, USA, 2000) including some Portuguese food items, which allow the quantification of different macro and micronutrients. Nutrient values were calculated from foods and supplements.

\subsection{Statistical analysis}

Differences in genotype frequencies, Fisher's exact tests and Hardy-Weinberg tests were calculated by GENEPOP (version 3.4). Statistical analysis was performed using SPSS version 16.0 for Windows (SPSS Inc., Chicago, EUA 2007). Data were expressed as mean \pm standard deviation, as number of subjects and (percentage) or as Odds ratio (OR) and 95\% confidence interval (CI). Bivariate analyses were conducted using Student's $t$-test or Mann-Whitney test for continuous variables and chi-square test for categorical ones. Multiple logistic regressions were used to study the association between variables and disease activity.

Statistical significance was established for $p<0.05$.

Subjects were classified as homozygous for the variant if they carried two mutated alleles, heterozygous if they carried only one mutated allele, and finally homozygous for the wild type when they had no mutant alleles. When analyzing the interaction between genetic and nutritional variables, the median value for each nutrient was considered.

\subsection{Ethical issues}

The study was approved by the Ethics and Scientific Committees of Instituto Português de Oncologia Francisco Gentil S.A (IPOFG) and Hospital Santa Maria. All subjects gave their informed and written consent before entering the study.

\section{Results}

Clinical features and demographics of study population are described in Table 1 . Ninety nine consecutive outpatients with a confirmed diagnosis of CD (60F:39M, mean age $40.4 \pm 14.6$ years) had a stable body weight during the 3 months preceding the study. According to the Harvey and Bradshaw Index (HBI), 36/99 (36.4\%) of patients had moderately active disease with an $\mathrm{HBI} \geq 4$ whereas 
Table 1

Clinical features of study population. ${ }^{a}$

\begin{tabular}{|c|c|c|}
\hline Clinical features & Cases \% $(N)$ & Controls \% $(N)$ \\
\hline Age (years) ${ }^{b}$ & $40.4 \pm 14.6$ & $59.7 \pm 11.8$ \\
\hline \multicolumn{3}{|l|}{ Gender } \\
\hline Male & $39.4(39)$ & $44.0(51)$ \\
\hline Female & $60.6(60)$ & $56.0(65)$ \\
\hline Smoking habits & $14.2(30)$ & $48.1(102)$ \\
\hline Years of disease ${ }^{b}$ & $11.2 \pm 8.9$ & - \\
\hline \multicolumn{3}{|l|}{ Disease location } \\
\hline Ileum & $29.3(29)$ & - \\
\hline Colon & $17.2(17)$ & - \\
\hline Ileum + Colon & $53.5(53)$ & - \\
\hline \multicolumn{3}{|l|}{ Disease phenotype } \\
\hline Inflammatory & $27.3(27)$ & - \\
\hline Penetrating & $34.3(34)$ & - \\
\hline Stricturing & $38.4(38)$ & - \\
\hline \multicolumn{3}{|l|}{ Harvey-Bradshaw Index } \\
\hline$\leq 3$ & $64.3(63)$ & - \\
\hline$\geq 4$ & $35.7(36)$ & - \\
\hline Previous surgery & $49.5(49)$ & \\
\hline \multicolumn{3}{|c|}{ Current and past medication } \\
\hline Previous corticotherapy & $80.8(80)$ & - \\
\hline Metothrexate & $6.2(6)$ & - \\
\hline Azathioprine & $78.4(76)$ & - \\
\hline Infliximab & $1.0(1)$ & - \\
\hline
\end{tabular}

a $N=99$ patients with Crohn's disease and 116 healthy controls.

b $\bar{x} \pm \mathrm{SD}$.

the remaining $63(63.6 \%)$ had inactive disease. These activity indices refer to at least three visits during the 1-year period. Although controls were slightly older as compared to CD patients $(49.7 \pm 11.8$ vs $40.4 \pm 14.6 ; p<0.01)$ gender distribution was similar in both groups (65F:51M vs 60F:39M).

For the genetic analysis of the population we studied the genotypic frequencies (Table 2). Except for the PPAR $\gamma+161 \mathrm{C} / \mathrm{T}$ in controls, all polymorphisms were in Hardy-Weinberg equilibrium. When examining whether any of the polymorphisms studied had any influence in increasing the risk of developing Crohn's disease, we didn't observe any significant differences in odds ratio. The same applies to SNPs analyses and disease activity (Table 3), thereby suggesting that none of these SNPs alone, or in conjunction (data not shown) predispose to a more active phenotype. Also, no significant association was observed between SNPs analyzed and disease location, phenotype, age of disease onset or other characteristics of disease (Data not shown). Table 4 shows the association

Table 2

Genotypic frequencies. Odd ratio for disease susceptibility. ${ }^{\mathbf{a}}$

\begin{tabular}{lll}
\hline Polymorphism & $\begin{array}{l}\text { Genotypic frequencies } \\
\text { case/control \% }(N)\end{array}$ & O.R $(95 \% \text { C.I })^{\mathrm{b}}$ \\
\hline CASP9 $+93 \mathrm{C} / \mathrm{T}$ & $52.5(52) / 66.7(76)$ & 1 \\
CC & $43.4(43) / 31.6(37)$ & $1.64(0.80-3.36)(\mathrm{Ns})$ \\
CT & $4.0(4) / 1.8(3)$ & $1.03(0.17-6.38)(\mathrm{Ns})$ \\
TT & & \\
FASLG-843 C/T & $35.4(35) / 28.1(33)$ & 1 \\
CC & $42.4(42) / 55.3(64)$ & $0.60(0.27-1.29)(\mathrm{Ns})$ \\
CT & $22.2(22) / 16.7(19)$ & $1.02(0.38-2.73)(\mathrm{Ns})$ \\
TT & & \\
PPAR $\gamma$ Pro12Ala & $82.2(74) / 81.6(95)$ & 1 \\
CC & $16.7(15) / 16.7(19)$ & $1.04(0.04-29.56)(\mathrm{Ns})$ \\
GC & $1.1(1) / 1.8(2)$ & $0.96(0.38-2.44)(\mathrm{Ns})$ \\
GG & & - \\
PPAR $\gamma+161 \mathrm{C} / \mathrm{T}$ & $93.8(90) / 100(116)$ & - \\
TT & $6.3(6) / 0$ & \\
CT & $0 / 0$ & \\
CC & & \\
\hline
\end{tabular}

Ns, not significant.

a $\mathrm{N}=99$ patients in the case group and $N=116$ in the control group.

b OR (Multiple Logistic Regression) was adjusted for age and gender.
Table 3

Influence of polymorphisms genotype on CD activity. ${ }^{\mathbf{a}}$

\begin{tabular}{lllll}
\hline Polymorphism & $\begin{array}{l}\text { Inactive } \\
\text { disease } \%(N)\end{array}$ & $\begin{array}{l}\text { Active } \\
\text { disease } \%(N)\end{array}$ & $p$ value $^{\mathrm{b}}$ & O.R $(95 \% \text { C.I })^{\mathrm{c}}$ \\
\hline CASP9+93 C/T & & & & \\
CC & $34.7(34)$ & $18.4(18)$ & Ns & 1 \\
CT & $26.5(26)$ & $16.3(16)$ & & $1.13(0.48-2.65)$ \\
TT & $3.1(3)$ & $1.0(1)$ & & $0.68(0.06-6.87)$ \\
FASLG-843 C/T & & & \\
CC & $21.4(21)$ & $13.3(13)$ & Ns & 1 \\
CT & $26.5(26)$ & $16.3(16)$ & & $1.03(0.40-2.63)$ \\
TT & $16.3(16)$ & $6.1(6)$ & & $0.65(0.20-2.13)$ \\
PPAR $\gamma$ Pro12Ala & & & & \\
CC & $53.9(48)$ & $29.2(26)$ & Ns & 1 \\
GC & $10.1(9)$ & $5.6(5)$ & & $0(0)$ \\
GG & $1.1(1)$ & $0(0)$ & & $1.19(0.35-4.09)$ \\
PPAR $\gamma+161 C / T$ & & & & \\
TT & $60.0(57)$ & $33.7(32)$ & Ns & 1 \\
CT & $3.2(3)$ & $3.2(3)$ & & $2.33(0.41-13.13)$ \\
CC & - & - & & \\
\hline
\end{tabular}

Ns, not significant.

${ }^{\text {a }}$ High activity was defined if Harvey-Bradshaw Index $\geq 4$.

b $P$ values are from chi-square test.

c OR (Multiple Logistic Regression) was adjusted for age and gender.

between different types of fat intake and disease activity. We observed that a higher intake of total, saturated and monounsaturated fat was associated with a higher risk for active disease [O.R (95\% C.I) 2.56 (1.08-6.03); O.R (95\% C.I) 3.56 (1.46-8.65); O.R (95\% C.I) 3.32 (1.38-7.95), respectively]. Also, patients with a higher n-6/n-3 PUFA intake had a significantly higher disease activity [O.R (95\% C.I) 2.30 (1.02-5.30)]. Regarding the percentage of energy coming from dietary fat we have a mean value of $32.89 \%$, with

Table 4

Influence of fat intake ${ }^{\mathbf{a}}$ on CD activity.

\begin{tabular}{|c|c|c|c|c|}
\hline & $\begin{array}{l}\text { Inactive } \\
\text { disease } \%(N)\end{array}$ & $\begin{array}{l}\text { Active } \\
\text { disease \% }(N)\end{array}$ & $p$ value $^{\mathrm{c}}$ & OR $(95 \% \mathrm{CI})^{\mathrm{d}}$ \\
\hline \multicolumn{5}{|l|}{ Total fat } \\
\hline High & $42.9(27)$ & $65.7(23)$ & \multirow[t]{2}{*}{$<0.01$} & $2.56(1.08-6.03)$ \\
\hline Low & $57.1(36)$ & $34.3(12)$ & & 1 \\
\hline \multicolumn{5}{|c|}{ Saturated fat } \\
\hline High & $41.3(26)$ & $71.4(25)$ & \multirow[t]{2}{*}{$<0.01$} & $3.56(1.46-8.65)$ \\
\hline Low & $58.7(37)$ & $28.6(10)$ & & 1 \\
\hline \multicolumn{5}{|c|}{ Monounsaturated fat } \\
\hline High & $39.7(25)$ & $68.6(24)$ & \multirow[t]{2}{*}{$<0.01$} & $3.32(1.38-7.95)$ \\
\hline Low & $60.3(38)$ & $31.4(11)$ & & 1 \\
\hline \multicolumn{5}{|c|}{ Polyunsaturated fat } \\
\hline High & $46(29)$ & $57.1(20)$ & \multirow[t]{2}{*}{ Ns } & $1.56(0.68-3.60)$ \\
\hline Low & $54(34)$ & $42.9(15)$ & & 1 \\
\hline \multicolumn{5}{|c|}{ Trans fat } \\
\hline High & $44.4(28)$ & $60(21)$ & \multirow[t]{2}{*}{ Ns } & $1.86(0.81-4.34)$ \\
\hline Low & $55.6(35)$ & $40(14)$ & & 1 \\
\hline \multicolumn{5}{|c|}{ n-3 PUFA } \\
\hline High & $47.6(30)$ & $48.6(17)$ & \multirow[t]{2}{*}{ Ns } & $1.04(0.45-2.38)$ \\
\hline Low & $52.4(33)$ & $51.4(18)$ & & 1 \\
\hline \multicolumn{5}{|c|}{ n-6 PUFA } \\
\hline High & $44.4(28)$ & $60(21)$ & \multirow[t]{2}{*}{ Ns } & $1.88(0.81-4.34)$ \\
\hline Low & $55.6(35)$ & $40(14)$ & & 1 \\
\hline \multicolumn{5}{|c|}{ n-6/n-3 ratio } \\
\hline High & $47.6(30)$ & $57.1(20)$ & \multirow[t]{2}{*}{0.04} & $2.30(1.02-5.30)$ \\
\hline Low & $52.4(33)$ & $42.9(15)$ & & 1 \\
\hline
\end{tabular}

The cut-off points were for total fat $=76.7 \mathrm{~g}$, saturated fat $=24.7 \mathrm{~g}$, monounsaturated fat $=33.3 \mathrm{~g}$, polyunsaturated fat $=11.5 \mathrm{~g}$, trans fat $=0.7 \mathrm{~g}$, and $\mathrm{n}-3$ PUFA $=1.2 \mathrm{~g} ; \mathrm{n}-6$ PUFA $=7.6 \mathrm{~g} ; \mathrm{n}-6 / \mathrm{n}-3=7.3$.

Ns, not significant.

${ }^{\text {a }}$ Low or high intake refers to values above or under nutrient median intake.

b High activity was defined if Harvey-Bradshaw Index $\geq 4$.

c $\mathrm{P}$ values are from chi-square test.

d OR was determined using the values above or under nutrient median intake. OR (Multiple Logistic Regression) was adjusted for age and gender. 
a range between 17.41 and 52.78 , and we have observed a mean value of $32.81 \%$ for patients with inactive Crohn's disease and $33.27 \%$ for patients with a more aggressive disease, although these differences are not statistically significant $(p=0.722)$.

Interactions between dietary fat and polymorphisms of apoptotic genes on disease risk are shown in Table 5. Only significant associations are displayed. To increase statistical power in diet-gene association, risk was assessed combining the heterozygous and variant homozygous against the reference category of homozygous for the more frequent allele. In respect to total fat which per se, was already associated with a more active phenotype, we observed that the proinflammatory effect of a high total fat intake was more prominent in wild type carriers of the CASP9+93C/T polymorphism [O.R (95\% CI) 4.64 (1.27-16.89)]. The same applies to a high trans fat intake [O.R (95\% CI) 4.84 (1.34-17.50)]. In respect to the intake of saturated and monounsaturated fat, the magnitude of being associated with a more active phenotype was similar for both wild type as well as polymorphic allele carriers (Table 5). In regard to the PPAR $\gamma$ Pro12Ala SNP, we also observed that a high intake of saturated and monounsaturated fat was associated to a more active disease, but in wild type carriers only [OR (95\%IC) $4.21(1.33-13.26)$ and 4.37 (1.52-12.51), respectively]. Finally, a high intake of n-6 PUFA was associated with a more active phenotype, again in wild type carriers only for the FASLG-843C/T polymorphism [O.R (95\% CI) 5.15 $(1.07-24.74)]$.

\section{Discussion}

Previous studies have shown that in $\mathrm{CD}$ one of the basic pathogenic defects is resistance to apoptosis, namely of T-cells, which certainly contributes to perpetuate inflammation in the intestinal mucosa. It is also clear from previous studies that SNPs in various genes, namely apoptotic ones, may explain not only the

Table 5

Influence of the interaction between dietary ${ }^{\mathbf{a}}$ and apoptotic polymorphisms in $\mathrm{CD}$ activity.

\begin{tabular}{lll}
\hline \multicolumn{3}{c}{ Polymorphism } \\
\cline { 2 - 3 } & Wild type & With variant \\
\hline Total fat/CASP9+93C/T & $4.64(1.27-16.89)$ & \\
High & 1.0 & $2.87(0.79-10.52)$ \\
Low & $6.14(1.52-24.86)$ & $2.23(0.57-8.64)$ \\
Saturated fat/CASP9+93C/T & $5.14(1.21-21.75)$ \\
High & 1.0 & $2.03(0.47-8.70)$ \\
Low & $3.48(0.98-12.29)$ & \\
Monounsaturated fat/CASP9+93C/T & $3.78(1.03-13.92)$ \\
High & 1.0 & $1.27(0.32-5.07)$ \\
Low & $4.84(1.34-17.50)$ & \\
Trans fat/CASP9+93C/T & $2.27(0.60-8.49)$ \\
High & 1.0 & $3.04(0.80-11.54)$ \\
Low & $4.21(1.33-13.26)$ & \\
Saturated fat/PPAR $\gamma$ Pro1a 12 Ala & $2.57(0.35-18.87)$ \\
High & 1.0 & $2.41(0.45-12.89)$ \\
Low & $4.37(1.52-12.51)$ & \\
Monounsaturated Fat/PPAR $\gamma$ Pro12Ala & $1.66(0.26-10.47)$ \\
High & 1.0 & $3.04(0.54-17.14)$ \\
Low & $5.15(1.07-24.74)$ & \\
n-6 PUFA/FASLG-843C/T & $2.35(0.54-10.11)$ \\
High & 1.0 & $2.26(0.53-9.69)$ \\
Low & &
\end{tabular}

Analyzed by multiple logistic regression. OR, adjusted for age and gender was determined using the values above or under nutrient median intake. The cut-off points were for total fat $=76.7 \mathrm{~g}$, saturated fat $=24.7 \mathrm{~g}$, monounsaturated fat $=$ $33.3 \mathrm{~g}$, trans fat $=0.7 \mathrm{~g}$ and $\mathrm{n}-6$ PUFA $=7.6 \mathrm{~g}$. Combined genotype CC +93 CASP9, CC Pro12Ala PPAR $\gamma$, CC -843 FASLG and low intake was the reference category. All tests interactions showed $p>0.05$

a Low or high intake refers to values above or under nutrient median intake.

b High activity was defined if Harvey-Bradshaw Index $>4$. heterogeneous phenotypes but also the different responses to similar treatments. Thus, Hlavaty and colleagues ${ }^{16}$ recently demonstrated that polymorphisms in FASLG/FAS system and CASP9 influence the response to Infliximab in luminal and fistulizing Crohn's disease.

These observations were also the rationale to explore the associations between these same SNPs and dietary fat intake. A number of previous experimental and human studies have shown that dietary fat has the capacity of influencing cellular kinetics by interfering with crucial processes such as apoptosis induction, cell proliferation and cell differentiation. Thus, in an experimental study using cell lines, Llor et al. ${ }^{8}$ showed that supplementation with fish oil and olive oil resulted in an induction of apoptosis which could be an explanation for the putative beneficial effect of these fatty acids in the treatment of CD.

Therefore, in the present study we examined whether there was any interaction between SNPs of apoptotic genes and dietary fat intake in modulating disease activity in CD patients.

When analyzing the effect of fat intake per se in modulating disease activity, we observed that a high intake of total, saturated and monounsaturated fat was associated with more active disease which is consistent with previous findings of Pischon et al. ${ }^{17}$, where the results suggest that the combination of both $n-6$ and $n-3$ types of fatty acids is associated with the lowest levels of inflammation. In contrast, SNPs of apoptotic genes did not show any significant association with increased susceptibility to develop CD or to exhibit a more active phenotype.

Caspase-9 (1p36) is an apoptosis-related cystein protease, which upon binding with cytochrome $c$ and Apaf-1 forms an apoptosome complex and activates the executive caspases 3, 6 and $7 .^{18}$ Sequential activation of caspases plays a central role in the execution-phase of cell apoptosis. ${ }^{18}$ To our knowledge the functionality of this polymorphism is not yet known. The fact that, in the present study we observed that a high intake of total and trans fat was associated with a more active phenotype, mainly in wild type carriers, leads us to hypothesize that wild type carriers might exhibit more resistance to apoptosis and, therefore there would be a synergism between two potentially harmful factors. This is also consistent with the observations by Hlavaty et al. ${ }^{16}$ who observed that homozygotes for the polymorphic allele had a better response to Infliximab. However, this might not be straightforward as a high intake of saturated and monounsaturated fat, which by themselves are already associated to a more active phenotype, have comparable effect both in wild type as well as in polymorphic allele carriers.

$P P A R \gamma(3 \mathrm{p} 25)$ encodes a member of the peroxisome proliferatoractivated receptor (PPAR) subfamily of nuclear receptors. ${ }^{19}$ Rare PPAR $\gamma$ polymorphisms were found to be associated with human Crohn's disease. ${ }^{19}$ PPAR $\gamma$ inhibits NFKB activity, which forms part of a central signaling pathway that stimulates the transcription of multiple genes that encode proinflammatory molecules, and diets enriched with n-3 fatty acids are powerful PPAR $\gamma$ activators, which may be a plausible explanation for the anti-inflammatory effects of these fatty acids. ${ }^{20} \mathrm{~A}$ common structural polymorphism in the $P P A R \gamma$ gene, exon 1 (CCA-GCA, producing a Pro $\rightarrow$ Ala substitution at codon 12), has been described. ${ }^{20}$ This amino acid is located in the PPAR $\gamma$ domain that enhances ligand-independent activation. The Pro $\rightarrow$ Ala change may cause a conformational change in the protein, ${ }^{21}$ and thus patients wild type carriers of this polymorphism would have less inhibition of NFKB pathway and therefore would exhibit a more aggressive and active phenotype. Thus, our results are consistent with the observations that a synergism between a high intake of saturated and monounsaturated fat exists, thereby leading to a more active disease.

In regard to FAS receptor (FAS, CD95) and FAS ligand (FASLG, CD95LG) these are complementary members of a particular 
apoptotic pathway which play a major role in immune regulation. ${ }^{18}$ Recent studies suggest that FAS-mediated apoptosis is involved in the pathogenesis of IBD. ${ }^{22,23}$ FASLG (1q23) is a key apoptosis inducing ligand of the TNF family of death factors. ${ }^{18}$ The FASLG$843 \mathrm{C} / \mathrm{T}$ polymorphism is located in the promoter region in a binding site for the CAAT enhancer protein. ${ }^{24} \mathrm{~A}$ recent study reported that carriers of the $C$ allele of this polymorphism have a threefold increased binding capacity to the CAAT enhancer protein and subsequently a threefold higher expression of FASLG that leads to an increase of apoptosis of the active cells which are expressing FAS. ${ }^{16,24}$ Thus, wild type carriers would be more susceptible to apoptosis and, theoretically, exhibit a less severe phenotype. We observed that a high intake of n-6 PUFA, which is known to promote inflammation, was more deleterious in wild type carriers, as opposed to what could be expected. The reasons for these inconsistencies are not clear but it is worth recalling that interactions between nutrients and genes may be extremely complex. Furthermore, there are at least two main pathways of apoptosis. The extrinsic pathway induced by so-called death ligands, i.e. FAS dependent, and the intrinsic one. We may hypothesize that n-6 PUFA influence cellular apoptosis by interfering in the intrinsic pathway which does not involve the FASLG. On the other hand, Grimble et al. ${ }^{10}$ when examining in a group of healthy individuals the effect of a fish oil emulsion on cytokine production, observed that this suppressive effect was maximal when the basal production of cytokines was also maximal. Theoretically, the latter group would correspond to the most aggressive phenotype and therefore a beneficial effect could be harder to obtain, as opposed to what was observed. Therefore, a number of different hypotheses may have arisen to explain the results observed.

To our knowledge this is the first study examining the interaction between dietary fat intake and polymorphisms of apoptotic genes. Both are known to affect the rate of apoptosis in inflammatory cells which is known to be a major defect in the pathogenesis of $\mathrm{CD}$. However, this is an evolving field and the long accepted concept that saturated fat had a deleterious effect on chronic inflammation, is now called into question, since a recent experimental study showed that MCT oil, which is a saturated lipid, might prevent a form of colitis in an animal model. ${ }^{7}$ Thus, future studies examining the roles that these several types of dietary fat might exert in the treatment of $\mathrm{CD}$ according to specific genotypes, will be most welcome.

\section{Conflict of interest}

Potential competing interests: None of the authors had any financial or personal conflicts of interest related to this manuscript.

\section{Statement of authorship}

Specific author contributions: Ferreira P.: study design, data collection and analysis, polymorphism analysis and writing of the manuscript; Cravo M.: study design, patient inclusion from Instituto Português de Oncologia and clinical data collection, data analysis and writing of the manuscript; Guerreiro C.S.: nutritional evaluation of patients, data collection, data analysis and manuscript preparation; Tavares L and Moura Santos P.: patient inclusion from Hospital Santa Maria and clinical data collection and Brito M.: polymorphism analysis and manuscript preparation.

\section{Acknowledgment}

Financial support: This study was partly funded by a grant from Sociedade Portuguesa de Gastrenterologia.

\section{References}

1. Ahmad T, Armuzzi A, Bunce M, Mulcahy-Hawes K, Marshall SE, Orchard TR, et al. The molecular classification of the clinical manifestations of Crohn's disease. Gastroenterology 2002;122:854-66.

2. Satsangi J, Morecroft J, Shah NB, Nimmo E. Genetics of inflammatory bowel disease: scientific and clinical implications. Best Pract Res Clin Gastroenterol 2003;17(1):3-18.

3. Louis E, Satsangi J, Roussomoustakaki M, Parkes M, Fanning G, Welsh K, et al. Cytokine gene polymorphisms in inflammatory bowel disease. Gut 1996;39:705-10.

4. Souza HS, Tortori CJ, Castelo-Branco MT, Carvalho AT, Margallo VS, Delgado CF, et al. Apoptosis in the intestinal mucosa of patients with inflammatory bowel disease: evidence of altered expression of FasL and perforin cytotoxic pathways. Int J Colorectal Dis 2005;20:277-86.

5. Teitelbaum JE, Walker WA. Review: the role of omega 3 fatty acids in intestinal inflammation. J Nutr Biochem 2001;12:21-32.

6. Gassull MA, Fernández-Bañares F, Cabré E, Papo M, Giaffer MH, SánchezLombraña JL, et al. Fat composition may be a clue to explain the primary therapeutic effect of enteral nutrition in Crohn's disease: results of a double blind randomized multicentre European trial. Gut 2002;51:164-8.

7. Mañé J, Pedrosa E, Lorén V, Ojanguren I, Fluvià L, Cabré E, et al. Partial replacement of dietary (n-6) fatty acids with medium-chain triglycerides decreases the incidence of spontaneous colitis in interleukin-10-deficient mice. J Nutr 2009;139(3):603-10.

8. Llor X, Pons E, Roca A, Alvarez M, Mañé J, Fernández-Bañares F, et al. The effects of fish oil, olive oil, oleic acid and linoleic acid on colorectal neoplastic processes. Clin Nutr 2003;22(1):71-9.

9. Sadeghi S, Wallace FA, Calder PC. Dietary lipids modify the cytokine response to bacterial lipopolysaccharide in mice. Immunology 1999;96:404-10.

10. Grimble R, Howell W, O'Reilly G, Turner S, Markovic O, Hirrell S, et al. The ability of fish oil to suppress tumour necrosis factor $\mathrm{x}$ production by peripheral blood monuclear cells in healthy men is associated with polymorphisms in genes that influence tumour necrosis factor $\alpha$ production. Am J Clin Nutr 2002:76:454-9.

11. Guerreiro CS, Ferreira P, Tavares L, Santos PM, Neves M, Brito M, et al. Fatty acids, IL-6 and TNF- $\alpha$ polymorphisms: an example of nutrigenetics in Crohn's disease. Am J Gastroenterol 2009;104(9):2241-9.

12. Lennard-Jones JE. Classification of inflammatory bowel disease. Scand $J$ Gastroenterol 1989;24(170):2-6.

13. Harvey RF, Bradshaw JM. A simple index of Crohn's-disease activity. Lancet 1980;1(8167):514.

14. Sambrook J, Maniatis T, Fritsch EF. Molecular cloning: a laboratory manual. 2nd ed. Cold Spring Harbor, New York: Cold Spring Harbor Laboratory Press; 1989.

15. Lopes C.M. Reprodutibilidade e validação do questionário semiquantitativo de frequência alimentar. In: alimentação e Enfarte agudo do miocárdio: estudo de caso-controlo de base comunitária. Tese de Doutoramento Porto 2000;pp. 78-115.

16. Hlavaty T, Pierik M, Henckaerts L, Ferrante M, Joossens S, van Schuerbeek N, et al. Polymorphisms in apoptosis genes predict response to infliximab therapy in luminal and fistulizing Crohn's disease. Aliment Pharmacol Ther 2005;22:613-26

17. Pischon T, Hankinson SE, Hotamisligil GS, Rifai N, Willett WC, Rimm EB, et al. Habitual dietary intake of n-3 and n-6 fatty acids in relation to inflammatory markers among US men and women. Circulation 2003;108:155-60.

18. Srivastava R. Apoptosis, cell signaling, and human diseases - molecular mechanisms, vol. 2. Totowa, New Jersey: Humana Press Inc.; 2007.

19. Fajas L, Auboeuf D, Raspé E, Schoonjans K, Lefebvre AM, Saladin R, et al. The organization, promoter analysis, and expression of the Human PPARg Gene. $J$ Biol Chem 1997;272(30):18779-89.

20. Debril MB, Renaud JP, Fajas L, Auwerx J. The pleiotropic functions of peroxisome proliferator-activated receptor $\gamma$. J Mol Med 2001;79:30-47.

21. Gong Z, Xie D, Deng Z, Bostick RM, Muga SJ, Hurley TG, et al. The PPARg Pro12Ala polymorphism and risk for incident sporadic colorectal adenomas. Carcinogenesis 2005;26(3):579-85.

22. Xia B, Yu YH, Guo QS, Li XY, Jiang L, Li J. Association of Fas-670 gene polymorphism with inflammatory bowel disease in Chinese patients. World $J$ Gastroenterol 2005;11(3):415-7.

23. Bu P, Keshavarzian A, Stone DD, Liu J, Le PT, Fisher S, et al. Apoptosis: one of the mechanisms that maintains unresponsiveness of the intestinal mucosal immune system. J Immunol 2001;166:6399-403.

24. Wu J, Metz C, Xu X, Abe R, Gibson AW, Edberg JC, et al. A novel polymorphic CAAT/enhancer-binding protein $\beta$ element in the FasL gene promoter alters FasLigand expression: a candidate background gene in African American systemic Lupus Erythematosus patients. J Immunol 2003;170:132-8. 